\title{
Buying up the Block: An Experimental Investigation of Capturing Economic Rents Through Sequential Negotiations*
}

\author{
Gautam Goswami \\ Gabelli School of Business, Fordham University \\ Thomas Noe \\ Balliol College/Saïd Business School, University of Oxford \\ email: thomas.noe@sbs.ox.ac.uk
}

Jun Wang

Baruch College, CUNY

\begin{abstract}
This paper analyzes an economic experiment designed to measure the effect of "legal technology" on the economic efficiency of Coasian bargaining. In the experiment, the agreement of many agents (called "landowners") to transfer their property rights to a single agent (called "the developer") generates an economic surplus. In this setting, we show that a very primitive legal technology sequential cash purchase (SC-P) is a strong implementation of a unique efficient bargaining outcome as a subgame-perfect equilibrium. However, when deployed in the laboratory, SC-P results in an average loss of $60 \%$ of the economic surplus through inefficient negotiation failure. Deploying a more behaviorally robust but also more legally complex technology, a tender and conditional offer (TC-O) mechanism, halved the surplus loss and supported significant developer payoffs. These results suggest that, even absent asymmetric information, moral hazard, and transactions costs, complex legal technologies can increase bargaining efficiency.
\end{abstract}

\footnotetext{
${ }^{*}$ Goswami would like to thank Graduate School of Business of Fordham University for providing the experimental laboratory and financial support for running the experiments. The authors acknowledge research assistance from Wei Lai and Robert Chen. All errors are our own.
} 


\section{Introduction}

Under what conditions do private negotiations lead to efficient resource allocation? A necessary condition for efficiency is the absence of negotiation-related transactions costs. The Coase Theorem argues that this necessary condition is, in fact, sufficient. Most objections to the Coase Theorem center on the inefficiency of even transactioncost free negotiations. Game-theoretic models of negotiation have shown that in the presence of, for example, asymmetric information, equilibrium negotiation strategies involve inefficient delay. ${ }^{1}$ In fact, even under complete information, some bargaining mechanisms lead to inefficiency. ${ }^{2}$ However, there exist agent preferences, information specifications, and bargaining game structures under which all subgame perfect Nash equilibria produce efficient outcomes. We term such structures, "perfect settings." It seems that if the Coase Theorem ever has predictive power, it will have predictive power in perfect settings, settings where its assumptions are satisfied and its predictions correspond with the predictions of the standard solution concepts used by economic theorists.

Perfect settings are games, which, if they are deployed in actual negotiations, require some sort of legal/institutional technology to constrain agent choices to the choices prescribed by the game. The sophistication of the technology in terms of the demands it places on verifiability and commitment can vary widely across perfect settings. Although all perfect settings lead to efficiency when they are populated with idealized rational agents playing subgame perfect strategies, whether efficiency is attained by actual economic agents and whether the attainment of efficiency varies with the legal technology employed is an empirical question. Since it is not possible to ensure that any real-world negotiation satisfies the "perfect setting" assumption, the empirical analysis of this question is, of necessity, experimental.

Our paper investigates this question. The specific economic context for our experiment is designed to reproduce the bargaining problem used by Coase to exemplify Coasian bargaining — the railroad company/farmer negotiations, in which a single agent 
(the railroad), needs to acquire rights from many counterparties (the farmers) to implement a project that generates an economic surplus. The only real difference between our setting and Coase's is that we have updated the names of the agents: calling the single agent who can generate a surplus "the developer" rather than "the railroad" and the counterparties "landowners" rather than "farmers."

We develop this bargaining problem using two different perfect mechanisms. In the first, which we call the sequential, cash-purchase (SC-P) mechanism, the developer approaches landowners sequentially and, in the negotiations, offers and counteroffers propose terms for immediate cash purchase of land by the developer. Cash purchase does not require verification of contract conditions or verification of the outcome of developer and/or landowner actions in previous negotiations. Cash purchase contracts can be enforced by simple escrow accounts or by simple legal sanctions against theft and fraud. Moreover, cash purchases do not impose any duty to perform on the contract until the other party to the contract has performed. Thus, the cash purchase mechanism does not require enforcement of "executory" contracts. ${ }^{3}$ Therefore, simple seriatim cash purchase should be viable even in the most unsophisticated legal environment. In fact Hobbes [1983, Chapt. II-X] argues that natural prudence and right reason alone would lead parties to honor such agreements even in the absence of any state legal enforcement. $^{4}$

As well as relying on very simple legal technology, from a mechanism design perspective, the sequential cash-purchase mechanism is a "gold-standard" implementation of efficient bargaining: it is a strong implementation of an efficient bargaining outcome as the unique subgame perfect equilibrium of a perfect information game. ${ }^{5}$ Thus, judging SC-P by the standards of legal simplicity and unambiguous implementation, it appears to be an ideal mechanism for ensuring efficient bargaining. However, deploying the mechanism in an experimental setting quickly disabuses one of this notion. In the experiments deploying SC-P, $60 \%$ of the surplus was lost because of inefficient negotiation failure. Not only did negotiations frequently fail, they failed so often that 
the developer's average gain were essentially zero. Thus, our results suggest that, under SC-P, sequential negotiations is so inefficient that little ex ante incentive exists even to initiate negotiations aimed at capturing surplus through property rights reallocations.

Examining the data from the SC-P experiment, we find that the generally dismal performance of the SC-P mechanism can best be explained by the vulnerability of developers to landowners making irrational (non wealth maximizing), unpredictable responses to developer offers: Under SC-P, developer payments to landowners are sunk at the time of sale. Thus, if the developer has bought a parcel in a previous negotiation and a subsequent landowner is irrationally obdurate and refuses to sell, the surplus is lost and the developer is saddled with the cost of the previous land purchase. This behavioral risk lowers the developer's continuation value in early negotiations and thus the developer's offers. In the experiments, average accepted developer payments to landowners sum to $80 \%$ of the project value, exceeding the Nash equilibrium prediction but leaving considerable scope for developer gains if landowner responses were predictable. Unfortunately for the developers, actual landowner responses are a mixture of best-reply responses, fairness-based even-split responses, and a large number of apparently random responses.

Because our gold-standard (under the rational choice perspective) mechanism failed to even approximate efficient bargaining in the laboratory, and that the failure resulted from empirical agent behavior deviating from the rational-choice paradigm, we next investigate the question of whether modifying the legal technology would yield a more behaviorally robust implementation of efficient bargaining. The modified technology, which we term the tender and conditional-offer, TC-O. This mechanism employs realistic institutional mechanisms for property-rights acquisitions-tender-offers and conditional purchases-while, at the same time, not permitting precommitment by developers to spurn offers from "holdout" landowners. In the TC-O game, the developer makes a tender offer for each of the parcels simultaneously to all landowners. Those landowners (if any) who reject the tender offer, the holdouts, are then approached se- 
quentially by the developer for 1-1 negotiations in the continuation subgame. Both the continuation offers and the tender offer are conditional purchase offers, i.e., an agreed offer obligates the parties if and only if all other landowners also reach an agreement with the developer.

Like the SC-P, in the TC-O, all subgame perfect Nash equilibria are efficient. Thus, the game implements efficient bargaining and hence also represents a perfect setting. The two features that distinguish TC-O from the SC-P are the initial simultaneous tender offer and conditionality. The incorporation of a tender offer into the game design is motivated by the fact that one equilibrium of the TC-O game features a symmetric developer tender offer and produces symmetric landowner payoffs. Accepting this symmetric offer is a best-response both for rational wealth-maximizing landowners and landowners with preferences based on inter-landowner fairness. If the game lacked the initial tender offer phase, no pure-strategy equilibrium would exist that produced identical payoffs to all landowners. Sequential cash purchase (conditional) negotiations favor landowners late (early) in the negotiation sequence. Thus, under both the SC-P and TC-O mechanisms, sequential negotiations lead to asymmetric landowner payoffs. The tender offer phase permits developers, who are unsure whether landowners have expected wealth maximizing or fairness-based preferences, to make tender offers that will be accepted by both types of landowners.

In addition, because rejections void earlier purchase agreements, replacing cash purchase offers with conditional offers reduces the developer's losses from unpredictable offer rejections. Moreover, when offers are conditional, rational best responses for both the developer and landowner depend only on the amount of surplus that has not yet been committed in earlier negotiations. In contrast, under SC-P, reservation demands depend on the anticipated future actions of landowners later in the negotiating sequence. These two effects combined make the conditional sale mechanism more behaviorally robust to deviations from the common-knowledge-of-rationality assumption that underpins the Nash equilibrium concept. At the same time, the TC-O game requires 
enforcement of executory contracts, is not dominance solvable, is not a game of perfect information, and supports multiple equilibria. Thus, viewed either from the perspective of mechanism design or the perspective of legal simplicity it appears to be dominated by sequential cash purchase.

Nevertheless, in the experiment deploying of TC-O mechanism, bargaining efficiency was substantially higher than under SC-P. On average, approximately $35 \%$ of the surplus was lost through inefficient bargaining as opposed to $60 \%$ under SC-P. Moreover, developers, on average, captured significant gains, $25 \%$ of the surplus. Landowners captured the remaining $40 \%$. The major deviation from Nash equilibrium predicted payoffs in the TC-O resulted from inefficient negotiation failure reducing the actual surplus rather than from the division of the actual surplus deviating from the Nash predictions. In fact, conditioned on an efficient solution being reached, the observed average surplus division, $38 \%$ to the developer, was within the range of surplus allocations to the developer, $37 \%-40 \%$, that are supported by subgame perfect Nash equilibria. Inefficient negotiation failure in the TC-O treatments resulted primarily from developer offers below the minimum offer rationalizable by any Nash equilibria.

Our structured multi-agent bargaining experiments show that, even absent transactions costs, information asymmetry, or moral hazard, bargaining is substantially less efficient than predicted by the Coase Theorem. The degree of inefficiency is dependent on the choice of bargaining mechanism, even when equilibrium predicted efficiency is not. A complex but fairly realistic mechanism, which reduced the dependence of agent payoffs on the rationality of other negotiating parties, produced much more efficient outcomes than a simple perfect-information mechanism. The standard rational for complex contracting mechanisms and legally mandated negotiation regimes is that they overcome the obstacles to efficient contract negotiation generated by asymmetric information, unverifiability, and moral hazard [e.g., Baron and Holmström, 1980, Berkovitch et al., 1998]. The results in this paper suggest that such mechanisms have value even absent these impediments and that such mechanisms might have evolved to cope with 
behavioral risks generated by non-maximizing and non-Bayesian agent behavior. ,

\section{Related literature}

This paper is related to a number of strands of economic research. One strand is experimental research on structured bargaining games (Binmore et al. [1985], Ochs and Roth [1989]). In contrast to these papers, this paper considers negotiations which are sequential and feature more than two negotiating parties. This focus on multiagent sequential negotiations ties our work to a much smaller literature on multiagent sequential bargaining. Theoretical research in this area has analyzed a number of game forms and contracting structures for sequential multiagent bargaining which are generally more sophisticated than our simple framework. ${ }^{6}$ Experimental research on multiagent bargaining games is also limited. However, Collins and Isaac [2012] in a laboratory experiments show that the holdout problem can produce large inefficiencies and lost opportunities. They also show that contingent contracts can facilitate successful bargaining but, in contrast to our results, conditional contracting does not benefit buyers.

While the methods and approach employed in this paper are most closely tied to the experimental literature on structured bargaining, our research objectives are more closely linked to research on the validity of the Coase Theorem. Kahneman et al. [1990] experimentally test the "endowment effect" on the Coase Theorem. Hoffman and Spitzer [1982] consider 2 and 3-person unstructured full and limited information bargaining games and find that their results support the Coase Theorem. The key difference between their paper and ours is that Hoffman and Spitzer assume that all agents must negotiate a collective agreement. In our setting this assumption is equivalent to the developer committing not to negotiate with holdout landowners. Hoffman and Spitzer's experiment thus models bargaining when some sort of collective negotiation constraint is imposed on the bargaining agents, as in, e.g., bankruptcy negotiations under Chapter 11. Our framework, in contrast, more closely tracks free-form negotiations where there 
is no mechanism to enforce collective negotiation. ${ }^{7}$

\section{Mechanisms: Sequential Cash Purchase (SC-P)}

\subsection{The rules of the game}

We implemented a game in which a developer attempts to buy $n$ indivisible and identical parcels of land to complete a development project. Each parcel is owned by a single landowner. We normalize the value of a parcel to the landowner to 0. All $n$ parcels are required to complete the project and, if the project is not completed, the land has no value to the developer. If all $n$ parcels are acquired by the developer, then the value of the project to the developer is 1 dollar. Thus, the $n$ parcels of land are perfect complements and the economic surplus from the project is 1 dollar. The developer negotiates with each individual landowner only once and only through 1-1 bargaining. These negotiations relate to the size of the monetary payment the developer will make for a landowner's parcel. The developer and landowner have complete information regarding the history of the game. The developer is wealth unconstrained in that regardless of payments he has made in the past, he can still make any payment he chooses in current negotiations. In our experiment. We implemented the $n=3$ case which correspond to three 1-1 negotiations between a landowner and developer.

Each individual 1-1 negotiation is a two-period nonstationary version of an Osborne and Rubinstein [1990] bargaining game, where the delay associated with the rejection of each offer leads to a probability of value dissipation. When value dissipation occurs, the economic value of project falls to zero, terminating all negotiations between the developer and the landowners. Rejection of the first offer (made by the developer) engenders dissipation with probability $\frac{2}{3}$; rejection of the second offer (the counteroffer made by the landowner) engenders dissipation with probability 1 . This bargaining model reduces the individual 1-1 negotiation to a simple two-stage process in which the 
developer makes a initial offer, and a landowner makes the final counteroffer.

The specific structure of the model is as follows. First, the developer makes an "offer" to a landowner to buy her land. An offer is defined in our analysis as a payment proposed by the developer to a landowner. If the landowner accepts the offer, she receives the offer price and the negotiation with her ends. If she rejects the offer,

there is a probability $\frac{2}{3}$ that the value of the project is dissipated. With probability $\frac{1}{3}$, no value dissipation occurs. In this case, the landowner makes a "counteroffer" to the developer. A counteroffer is payment from the developer to the landowner proposed by the landowner. At this point, the developer can accept or reject the counteroffer. If the counteroffer is accepted, the developer acquires the parcel, makes the payment, and the negotiation with the given landowner ends. If the counteroffer is rejected, the value of the project falls to zero with probability 1 .

\subsection{Subgame perfect Nash Equilibrium}

Suppose that all agents are rational risk-neutral expected payoff maximizers. All payouts made by the developer in previous negotiation are sunk, and thus will be ignored in our analysis of subsequent negotiations. Hence, when we refer to "developer payoffs" in a given negotiation, we are not factoring in sunk payments made in previous negotiations. Sometimes, when we want to emphasize that sunk payments are not included in the payoff calculation, we shall refer to developer payoffs as "continuation payoffs." When we want to factor these sunk payments into our analysis, we shall use the term "total payoffs." Our negotiation game has a unique subgame perfect equilibrium, derived by backward induction. Consider first the last landowner in the negotiation sequence. To reach the last negotiation, the other landowners must have sold to the developer. Thus, the last landowner knows that if she refuses to sell, the developer cannot complete the project. If the landowner makes a counteroffer, she can demand any amount less than the full project value 1, with the assurance that her counteroffer will 
be accepted. An offer more than 1 would certainly be rejected by the developer because accepting such an offer produces a negative payoff to him, and he can receive a payoff of 0 in the last negotiation simply by rejecting the counteroffer. Since the landowner receives nothing when her offer is rejected, she will never ask for more than 1 . Thus, the landowner must receive 1 in a subgame starting with the landowner making a counteroffer. Hence, when the third landowner rejects a developer offer, with probability $\frac{2}{3}$, the project's value is dissipated, and with probability $\frac{1}{3}$ the landowner makes a counteroffer of 1 , which is accepted by the developer. The expected value to the last landowner from following the strategy of rejecting the developer's offer is thus $\frac{1}{3}$. Rationality dictates that the last landowner will accept any offer that is greater than $\frac{1}{3}$. The developer's payoff from making an offer that is rejected is zero. Thus, an offer less than $\frac{1}{3}$ will, if it is accepted by the landowner, produce a lower payoff than a rejected offer, and thus such an offer must be rejected. Since the developer always prefers his offer being accepted to being rejected, the developer must, in any subgame perfect equilibrium, make an offer of $\frac{1}{3}$ to the last landowner, and this offer must be accepted.

Hence, regardless of the amount paid to landowners of earlier successful negotiations, the developer knows that he will pay $\frac{1}{3}$ to buy out the last landowner. Meeting the last landowner's demands costs the developer $\frac{1}{3}$, leaving $1-\frac{1}{3}=\frac{2}{3}$ available for division between the developer and the second-to-last landowner. We call the value of the project not committed to landowners later in the negotiation sequence the "residual value" of the project. Through the same arguments used for the last negotiation, we can see that in the second-to-last negotiation, the landowner can capture $\frac{1}{3}$ of the residual value, i.e., $\frac{1}{3}\left(1-\frac{1}{3}\right)=\frac{2}{9}$. This implies that at the start of the first negotiation in the three-landowner game, the residual value is $1-\frac{1}{3}-\frac{2}{9}=\frac{4}{9}$. By the same argument again, the first landowner can capture one third of this residual value, or $\frac{4}{27}$. Thus, in any subgame perfect equilibrium, the developer's offer is accepted in each negotiation, and the developer offers $\frac{4}{27}$ to the first landowner, $\frac{2}{9}$ to the second landowner, and $\frac{1}{3}$ to the third landowner. These offers are the lowest offers the landowners will accept. If 
the developer's offer were to be rejected, the landowner should counter with an offer equal to three times the developer's offer, and the developer should accept this final offer if and only if the developer's payoff from this point is non-negative. These simple arguments motivate the following result.

Proposition 1. Let $e_{i}$ represent the landowner counteroffer when the landowner is the ith landowner approached by the developer; let $o_{i}$ be the offer the developer makes the ith landowner approached by the developer. The unique subgame perfect Nash equilibrium of the game is given by

1. Developer offers, $o_{i}$ are given by $o_{1}^{*}=\frac{4}{27}, o_{2}^{*}=\frac{2}{9}, o_{3}^{*}=\frac{1}{3}$.

2. Landowner's reject all developer offers less than $o_{i}^{*}$ and accept all offers greater than or equal to $o_{i}^{*}$

3. Landowner counteroffers, $c_{i}$ are given by $c_{1}^{*}=1-o_{2}^{*}-o_{3}^{*}, c_{2}^{*}=1-o_{3}^{*}, c_{3}^{*}=1$.

4. Developers reject all developer offers greater than $c_{i}^{*}$ and accept all offers less than or equal to $c_{i}^{*}$

Moreover, this equilibrium is the dominance solvable solution to the game and the total payoff to the developer and all the landowners equals 1, the total surplus generated by the property-rights transfer.

Proof. A formal derivation of this proposition is provided by Online Supplement A.

\section{Mechanism: Tender and Conditional Offer (TC-O)}

\subsection{Rules of the game}

The assumptions concerning agent valuations and preferences are the same in the TC-O game as in the SC-P game. Also, as in the sequential unconditional game, the individual 1-1 negotiation are a two-period nonstationary version of an Osborne and Rubinstein [1990] bargaining game. 
There are two key differences between the sequential unconditional game and the conditional offer game. First, under the conditional offer game, the developer's offers are conditional. Developer offers and landowner counteroffers stipulate an amount that the developer will pay the landowner conditioned on all landowners reaching agreements with the developer. If an agreement is not reached with any one landowner, the developer is not obligated to pay any payments to the landowners. The second difference is that, at the start of the game, the developer makes a simultaneous tender offer to all landowners. The tender offer consists of $n$ offers, one for each of the $n$ landowners. These $n$ offers need not to be identical. Rejection of the tender offer never leads to dissipation. If a landowner accepts the tender offer, this offer fixes the landowner's contract with the developer and the landowner "exits" the game. We call the set of landowners who reject the developer's tender offer the holdout set and the set of landowners who accept the developer's offer the acceptor set. If the holdout set is empty, the game ends after the initial tender offer phase and value is divided as specified by the conditional offer contracts.

If the holdout set is not empty then, the game proceeds. The developer picks a holdout landowner with whom he will enter into 1-1 negotiations. The 1-1 negotiations follow the pattern described above. This process continues with further 1-1 negotiations until either dissipation occurs, in which case all parties receive a zero payoff or contracts are fixed with all landowners, in which case, the conditional contracts divide the surplus, 1, among the landowners and developer. Thus, the game can be divided into two phases: the initial tender offer phase that consists of the developer's tender offer and the landowner responses and a sequential continuation phase where the developer sequentially approaches those landowners who did not agree to the tender offer for sequential 1-1 negotiations. We solve the game by working backwards, starting with the sequential continuation phase. 
Goswami

\subsection{Subgame perfect Nash equilibria}

\subsubsection{Sequential continuation phase}

The strategies of the developer and landowners in the sequential continuation phase are transparent. We will first verify in any subgame perfect equilibrium in which, in each sequential 1-1 negotiation, the developer offers the landowner $\frac{1}{3} r$, where $r$ represent the residual value available at the start of the given 1-1 negotiation. The residual value is the surplus from the project, 1 , less the value committed to landowners in either the initial tender offer phase or earlier 1-1 negotiations.

Consider first the developer's response to landowner counteroffers in a given 1-1 negotiation. Because, rejection of the counteroffer triggers dissipation with certainty, the developer's payoff from rejecting a counteroffer is zero. The developer's payoff from accepting counteroffers less than or equal to residual value is always non-negative. The developer's payoff from accepting counteroffers greater than residual value are always negative. Thus, a developer reservation strategy of accepting all counteroffers demands less than or equal to residual value and rejecting all offer in excess of residual value is a best response for the developer. Landowners earn nothing if they make an offer that will be rejected. So given the developer's counteroffer response strategy, a counteroffer demanding the entire residual value, $r$, is an optimal strategy for landowners. Since reaching the counteroffer stage in the 1-1 negotiations triggers dissipation with probability $\frac{2}{3}$. A reservation response strategy for the landowner of accepting developer offers if and only if they are at least equal $\frac{1}{3} r$ is a best accept/reject response strategy for landowners. Given that the developer earns zero payoffs from rejected offers, the optimal offer for the developer in the given 1-1 negotiation is to offer the landowner $\frac{1}{3} r$. Under the landowner's response, this offer will be accepted. Thus, in each of the 1-1 negotiation in the sequential continuation phase the developer will offer and the landowner will accept $\frac{1}{3} r$. 
Goswami

\subsubsection{Landowner and developer payoffs from the sequential continuation phase}

The actual offers made in the continuation phase depend on the residual value remaining after the initial tender offer phase and the number of holdout landowners. Let $h$ represent the number of holdout landowners. Let $r_{o}$ be the residual value at the start of the sequential continuation phase, i.e., $r_{o}$ equals the surplus less value committed to the landowners who have accepted initial tender offers. Then the offer to the first landowner in the sequential phase is $\frac{1}{3} r_{o}$, and the residual value after this negotiation is $\frac{2}{3} r_{o}$. Since the developer always offers $\frac{1}{3}$ of the residual value to the next landowner and this offer would be accepted in the equilibrium, the payoff to the developer in the sequential continuation phase is thus given by

$$
\Pi_{D}\left(h, r_{o}\right)=\left(\frac{2}{3}\right)^{h} r_{o}
$$

Although the sequence in which the developer approaches landowners has no effect on the developer's equilibrium payoff or the total payoff to landowners, sequencing does affect the payoffs to individual landowners. Equilibrium offers are declining in the landowner's position in the negotiation sequence. Thus, in contrast to the simple unconditional sequential SC-P game, landowners late in the sequence of negotiations receive smaller payoffs than those receiving early offers. This follows from conditionality: the more offers accepted, the smaller the residual value a landowner can extract by rejecting the developer's offer and making a counteroffer. The late position in the sequential negotiations lowers the landowner's reservation demands and thus, the developer's offer.

Because the game is symmetric, there is no reason for any landowner to expect any particular sequence of developer offers. Moreover, the developer is indifferent across negotiation sequences. For these reasons, we restrict attention to equilibria in which the developer follows a symmetric sequencing strategy, selecting the next landowner to be approached in 1-1 negotiations by randomizing uniformly over all of the remaining holdout landowners. Under this assumption, when there are $h$ holdouts, each landowner 
expects to be the $t$ th landowner approached with probability $1 / h$. Thus, the expected payoff to a landowner, $\Pi_{L}$, in the continuation phase given that $r_{o}$ residual value remaining after the initial tender offer phase and $h$ landowners holding out is given by averaging over the total value to holdout landowners.

$$
\Pi_{L}\left(h, r_{o}\right)=\frac{1}{h}\left(1-\left(\frac{2}{3}\right)^{h}\right) r_{o} .
$$

We record the results of this analysis in the next lemma.

Lemma 1. In the continuation phase, if the residual value after the completion of the initial tender offer phase is $r_{o}$ and there are $h$ holdout landowners remaining, then in any subgame perfect equilibrium in undominated strategies, the developer's payoff is given by equation (1) and the payoff to each holdout landowner is given by equation (2).

\subsubsection{The initial tender offer phase}

The analysis of the initial tender offer phase is substantially more complex than the analysis of the continuation phase. Complexity is introduced by simultaneous nature of the tender offer. Each landowner's best response to the developer's offer depends on the response of the other landowners. This dependence leads to multiple equilibria. Fortunately, as we shall show, the equilibrium payoffs in these equilibria are confined to a very narrow range. Because the formal analysis of these equilibria is somewhat involved and the payoff and response predictions are very similar across the equilibria, we defer the technical development of the results to Online Supplement B. Here we only summarize the logic.

A Nash equilibrium in the initial tender offer phase is a tender offer vector for the developer, $\alpha$, and a response function for the landowners. The landowners' response function is an accept/reject decision associated with each developer offer. The tender offer and response function constitute a Nash equilibrium if the developer's offer maximizes the developer's payoff given the landowner response function and, for each developer offer, the landowners' response functions are best responses given the response 
functions of the other landowners. Because, in equilibrium, all negotiations succeed in the continuation phase, the payoff to a landowner from accepting the tender offer is simply the tender offer of the developer. The payoff to the landowner from rejecting the offer is the equilibrium payoff to the landowner from being a holdout in the continuation phase conditioned on the other landowners' responses to the offer. The equilibrium payoff to the developer and the equilibrium payoff to the landowner from holding out are defined by the subgame perfect equilibrium in undominated strategies presented in Lemma 1.

The dependence of landowner best responses on the response of other landowners is illustrated by the following example. Consider a developer offer of $\frac{1}{5}$ to each landowner (i.e., $\alpha=\left(\frac{1}{5}, \frac{1}{5}, \frac{1}{5}\right)$ ). If the other landowners are following a strategy of accepting this offer, then a given landowner, say landowner 1 , will receive a payoff of $\frac{1}{5}$ if she accepts the offer. If she holds out she expects to be the lone holdout, $h=1$, and expects residual value to equal $1-2 \times \frac{1}{5}=\frac{3}{5}$. From equation (2) we see that her holdout payoff, $\Pi_{L}\left(h=1, r_{o}=\frac{3}{5}\right)$ equals $\frac{1}{5}$. So under the conjecture that other landowners will accept, acceptance is a best response for landowner 1. Now consider the same offer, $\alpha=\left(\frac{1}{5}, \frac{1}{5}, \frac{1}{5}\right)$ but assume that landowner 1 believes that the other landowners will reject the offer. In this case landowner 1's payoff from rejection is the payoff associated with three holdout landowners $(h=3)$ and a residual value of 1 . Again computing the landowner's payoff from rejection using (2), for $h=3$ and $r_{o}=1$ we see that her rejection payoff equals $\frac{19}{81}>\frac{1}{5}$, thus rejection is a best response for the landowner. In general, unless accepted developer offers are very small, the gain from holding out is increasing in the number of holdouts. This effect leads to multiple equilibria.

However, the range of payoffs that can be supported by multiple equilibria is fairly limited because the developer can make an offer that "forces" each landowner to conjecture that the others will accept. The forcing offer is structured as follows. Let $\max (\alpha)$ represent the highest developer offer to any landowner, $\operatorname{mid}(\alpha)$ the middle offer and $\min (\alpha)$ the lowest offer. Call the landowner receiving the $\max (\alpha)(\operatorname{mid}(\alpha), \min (\alpha))$ 
offer the max (mid, min) landowner. The forcing offer fixes $\max (\alpha)$ just high enough so that accepting the offer is a best response for the max landowner regardless of the accept/reject decisions of the other landowners. We call the offer that meets this condition $\alpha^{+}$. If $\alpha^{+}$is offered to the max landowner, then the mid landowner must, in any equilibrium, conjecture that the max landowner will accept. This lowers the reservation demands the mid landowner and the developer can then fix the offer to mid landowner so that the mid landowner is just willing to accept regardless of the accept/reject decision of the min landowner. We call this offer $\alpha^{o}$. In which case, the min landowner must in any equilibrium conjecture that the max and mid landowners will accept, lowering the min landowner's reservation demands. The developer can then fix the min offer so that the min landowner is just willing to accept. We call this offer, $\alpha^{-}$. Value in excess of these offers, $1-\left(\alpha^{+}+\alpha^{o}+\alpha^{-}\right)$places a floor on developer payoffs and ceiling on landowner payoffs. Similarly, the offer $\alpha=\left(\frac{1}{5}, \frac{1}{5}, \frac{1}{5}\right)$ produces the lowest total payments to the landowners over offers that all landowners will accept given all other landowners accept. Thus the offer $\alpha=\left(\frac{1}{5}, \frac{1}{5}, \frac{1}{5}\right)$ places a ceiling on developer payoffs and a floor on landowner payoffs. The ceiling and floor are quite close. Moreover, any division of value between the ceiling and floor can be supported by a subgame perfect Nash equilibrium and no division of value that is not between the ceiling and floor can be supported by a subgame perfect Nash equilibrium. This result is recorded below. It is also possible derive bounds on rationalizable developer offers. Tender offers outside these bounds cannot be part of any rationalizable solution of the game, i.e., any solution to the game where agents conjecture that other agents play best responses conditioned on consistent beliefs, beliefs that are self-fulfilling in the sense that under the conjectured beliefs the conjectured actions of other agents are best replies for those agents. In contrast to the Nash solution concept, rationalizability only imposes the condition that agent rationality is common knowledge while the Nash solution requires that the Nash equilibrium itself is common knowledge, i.e, in a rationalizable solution, agents can hold different consistent conjectures regarding the actions of other agents. Since we 
only use these bounds in one of our experimental tests and the bounds, in fact, have little predictive power, we defer their development to Lemma B.2 in Online Supplement B.

Proposition 2. Let

$$
\begin{gathered}
\alpha^{+}=\Pi_{L}[3,1]=\frac{19}{81}, \quad \alpha^{o}=\Pi_{L}\left[2,1-\alpha^{+}\right]=\frac{155}{729}, \quad \alpha^{-}=\Pi_{L}\left[1,1-\alpha^{+}-\alpha^{o}\right]=\frac{403}{2187} \\
D^{-}=1-\alpha^{+}-\alpha^{o}-\alpha^{-}=\frac{806}{2187} \approx 0.368541, \quad D^{+}=\frac{2}{5}=0.40 .
\end{gathered}
$$

Then

(a) for all $D \in\left[D^{-}, D^{+}\right]$there exists a Nash equilibrium of the conditional offer game that produces developer payoff equal to $D$ and landowner payoffs equal to $1-D$.

(b) All subgame perfect equilibrium the game produces developer payoffs between $D^{+}$ and $D^{-}$.

Proof. See Online Supplement B for proof of this proposition and see Lemma B.2 for the explicit conditions that a rationalizable offer must satisfy.

\section{Behavioral solutions}

Before we investigate the experimental results, we considerer some obvious behavioral biases that might influence agent behavior and induce deviations from rational Nash best replies. Under the SC-P mechanism, off the equilibrium path, the developer's equilibrium strategy calls for the developer to accept offers that generate negative total payoffs. Such acceptances are rational because payments to landowners reached earlier in the negotiation sequence are sunk and thus do not figure in a rational developers accept/reject decision. A rational developer will fix his reservation response to landowner counteroffers to that he accepts all offers that produce positive continuation payoff. Total payoffs are not decision relevant. However, the literature has documented that actual economic agents frequently exhibit sunk-cost bias, and factor sunk costs into their decisions. Because landowners only negotiate once with the developer and the developer's reservation value only factors into the developer's response to landowner counteroffers, 
sunk cost bias can directly affect the developer's response to landowner counteroffers. However, if the bias is common knowledge, it will affect the landowner's counteroffer and thus also the developer's offers through its effect on the developer's reservation response to final offers. Thus, for the SC-P mechanism we consider the sunk-cost solution. Under the TC-O mechanism, equilibrium strategies never call for the developer to accept offers that generate negative total payoffs for the simple reason that offer conditionality implies that total payoffs equal continuation payoffs and accepting offers generating negative continuation payoffs is never a rational best reply for the developer. Thus, under this mechanism sunk-cost bias is moot.

Under both mechanisms, fairness norms might affect agent behavior. In fact, "splitthe-difference" divisions of gains exhibit considerable predictive power in laboratory experiments [Roth and Malouf, 1979], even in experiments that set up a strategic bargaining game which has a Nash equilibrium solution inconsistent with the even-split solution (see Binmore et al. [1985]). For this reason, in our reports on the outcomes of both mechanisms, we shall frequently compare outcomes with the even split solution. In the case of the TC-O mechanism, with induces a simultaneous tender offer to all landowners, another focus for fairness norms is the symmetry of offers to the landowners. Thus, when discussing the TC-O mechanism we will sometimes focus our analysis on the effect of tender-offer symmetry.

\subsection{Sunk-cost solution: SC-P}

If developers ignore the fact that payments in earlier negotiations are sunk, they may set their reservation demands in the final offer stage at a level which insures that their total payoff is non-negative rather than the rational reservation level, which ensures that their continuation payoff is non-negative. We term the solution to the game under this assumption the sunk-cost solution. In the behavioral sunk-cost solution we assume that landowner reservation demands depend only on their position in the negotiation 
sequence and not on earlier offers of other landowners.

In this case, assuming that the developer's sunk cost bias is common knowledge, and otherwise agents are risk-neutral rational value maximizers, the counteroffer by each landowner must push the developer's payoff to the sunk-cost rejection threshold. Because landowners observe the payments made in previous negotiations, their computation of the developer's zero total payoff threshold is simple. Rational expectation requires that the developer's actual earlier offer be the same as the offer conjectured by the landowner. Moreover, for exactly the same reasons as we outlined in the analysis of the rational Nash solution, the developer's offer must equal one third of the landowner's counteroffer. Thus, if we let $c_{i}$ represent the equilibrium counteroffer of landowner $i$, $i=1,2,3$ and $o_{i}$ represents the developer's equilibrium offer to landowner $i$, we see that offers and counteroffers must satisfy the following system of equations:

$$
\begin{aligned}
\sum_{j \neq i} o_{j}+c_{i} & =1, & i & =1,2,3, \\
o_{i} & =\frac{1}{3} c_{i}, & i & =1,2,3 .
\end{aligned}
$$

This system of equations has a unique solution: $o_{i}=\frac{1}{5}, i=1,2,3 ; c_{i}=\frac{3}{5}, i=1,2,3$. Thus, using the same logic as applied to the rational value maximizing equilibrium, one can show that under the sunk cost solution agents follow the following strategies: the developer's offer is accepted in each negotiation and the developer offers $\frac{1}{5}$ to all landowners. This offer is the lowest offer the landowners will accept. If the developer's offer were to be rejected, the landowner should counter with an offer equal to $\frac{3}{5}$, and the developer should accept this counteroffer if and only if it is less than or equal to $\frac{3}{5}$. Landowners believe, regardless of the offer they receive from the developer, that the developer has paid $\frac{1}{5}$ to each landowner with whom he has previously negotiated. Other perfect Bayesian equilibria may exist under the sunk-cost assumption. In these more complex equilibria, landowner beliefs about earlier negotiations are affected by the developer's offer. And for reasons similar to those documented in McAfee and Schwartz [1994], dissipation may occur. However, given symmetry and simplicity of our sunk-cost solution, we believe that it is a natural solution when otherwise rational 
developer suffer from a sunk cost bias that leads him to avoid at all cost accepting offers that produce negative total payoffs.

\subsection{Even-split solution: SC-P and TC-O}

Under the assumption that agents demand fair payments and make fair offers, with "fair" being defined by the even division of the surplus from the project, we expect the developer's offer to be accepted in each negotiation and the developer to offer $\frac{1}{n+1}$ to each landowner, while $n$ is the number of landowners in the negotiation. This offer is the lowest offers the landowners will accept. If the developer's offer were to be rejected, the landowner should counter with an offer equal to $\frac{1}{n+1}$ and the developer should accept a final offer if and only if it is less than or equal to this counteroffer.

\section{The design of the experiment}

In the baseline experiment we set the number of landowner, $n$, equal to three. However, we also performed some experiments with one and two landowners as a robustness check. The results of these experiments are reported in the Online Supplement. Subjects for the experiment were recruited at a private university on the East Coast from a pool of undergraduate and graduate business students. ${ }^{8}$ Each student participated only in one experiment. The likelihood of contact between subjects in different experiments was minimized by recruiting students in different campuses, levels, and programs.

For each SC-P experimental session, we recruited up to 14 participants to play the two roles in the experiment, developer and landowner. We varied the number of landowners in each game as follows: For each SC-P experimental session, we recruited up to 14 participants to play the two roles in the experiment, developer and landowner. We varied the number of landowners in each game as follows: Game A with 1 landowner, Game B with 2 landowners and Game C with 3 landowners. 14 students were recruited to increase the likelihood that at least 12 students would show 
up. Since we needed either 1, 2 or 3 subjects to form one group of landowners and one developer, we decided to play each game with 12 subjects. For the TC-O session, we recruited 16 participants. The number of actual subjects is shown in Table 1 . When there were one or two participants in excess of required number of subjects, we "hired" the excess participants as assistants and paid them the average subject payoff. In each session, the subjects were taken into a classroom and provided with the instruction sheet, a decision tree and a consent form. First, the instruction sheet was read aloud. Next, subject questions were answered by the experimenter. Then the participants were asked to sign the consent form. After signing the consent forms, the subjects were taken into an experimental laboratory with 18 independent terminals, 4 in each row and 2 on one side. One terminal on the side was used as the experimenter's terminal. This terminal could observe all decisions taken by subjects at any point in time. The subjects are requested to write the terminal number on their result sheet. ${ }^{9}$

\section{$<<$ COMP: Place Table 1 about here $>>$}

The subjects were told that there would be no verbal discussions between the subjects but questions would be answered by one of the experimenters during four practice rounds. All negotiations were conducted by entering numbers on computer terminals. In SC-P sessions, as soon as the subjects were seated on a terminal and experimenter decided to play the A or B or C type game, 6,4 or 3 of the 12 subjects were randomly designated to be the developers. Then the rest of the subjects were randomly divided in 6 or 4 or 3 groups and in each group subjects were designated as landowner 1, 2, or 3. In the next round, the computer picked 6 or 4 or 3 developers from the earlier round landowners and continued to do so until all subjects are designated as developer once. The designation of developer and landowner as well as the formation of group changed from round to round throughout the experiment. Each experiment therefore, is equivalent to an independent game. But the developer's role was carefully allocated so that each subject played developer's role the same number of times. Developer total payoffs 
could be negative. However, landowner payoffs could never be negative. Because all subjects played the developer and landowner role an equal number of times, we were not required to pay a base payoff to subjects to avoid subjects receiving a negative total payoff in the experiment. We announced that experiment session might continue up to 20 rounds. However, subjects essentially played the game with indefinite end points since they were not told when the game would end. In TC-O session, the process is similar and all games have one developer and three landowners.

Landowners could observe the negotiations with other landowners on the computer terminal. Payoffs in the experiment where determined by setting the value of the parcel at 100 Francs, the experimental currency unit. Landowner payoffs equaled payments to the landowner by the developer and developer payoffs equaled 100 Francs less payments to the landowners if the negotiations succeeded and zero less payments to the landowners if negotiations failed. Each landowner and developer kept records of offers and counteroffers. The overall result of the round was shown to all the landowners and developers at the end of each round. Each experiment was repeated for several rounds, and each experiment session lasted less than one hour. At the end of each session, payoffs were calculated and payments were made to all subjects in less than 5 minutes. The total payoff to all participants was $\$ 1900$ for 5 sets of experimental session and 3 sessions of trial runs. Individual subject's dollar payoffs were determined by multiplying that subject's Franc payoff by the conversion factor 0.0625 . The average dollar payoff to subjects was $\$ 23.69$ for about one hour of their time.

\section{Outcomes of the SC-P game}

\subsection{Basic results}

We only report SC-P games with one developer negotiating with three landowners. Table 2 describes the incidence of failure in the negotiations. The most striking result 
in this table that $59 \%$ of negotiation ended in failure. These results are inconsistent with the Coase Theorem and with the predictions of the standard game theoretic models of behavior because, under the unique rational Nash outcome, the likelihood of negotiation failure is zero.

\section{$<<$ COMP: Place Table 2 about here $>>$}

Table 3 continues our investigation by considering the realized payoffs of the players. Total payoffs and the payoffs of each agent are below rational Nash predicted values. The shortfall is particularly pronounced for the developers: the average developer payoff is essentially 0 . Inspecting agent payoffs conditioned on offer success, we see that the average developer's payoff is higher and but still less than the theoretically predicted payoff. In fact, developer payoffs, on average, are closer to the even-split solution which divides the surplus equally between all of the players, than the predicted Nash payoff. These very low average payoffs to the developer seem to be the product of frequent breakdown in negotiations and, to a lesser extent, excessively generous developer offers.

\section{$<<$ COMP: Place Table 3 about here $>>$}

Frequent negotiation failures leading to dissipation in experimental simulation of structured bargaining games which support only efficient subgame perfect equilibria are not uncommon. As reported in the online supplement, for robustness treatments featuring a single landowner, rate of failure (about 31\%), as well as the propensity of subjects to make disadvantageous counteroffers and make even-split offers, was roughly consistent with the literature (see Ochs and Roth [1989]). However, in our multi-agent negotiation framework, failure has different consequences for agent payoffs than it does in single negotiation games. Because developer makes unconditional payments to the landowners, landowners who have reached agreements with the developer receive positive payoffs even when the negotiations fail at a later point in the negotiation sequence. 
So failure disproportionally affects those landowners later in the negotiation sequence. Because the developer cannot receive any gain unless all negotiations are successfully completed, failure's effect on the developer is even greater. The disproportionate effect of failure perhaps accounts both for the first landowner in the negotiation sequence having the highest average payoff as well as the insignificance of average developer payoffs.

Next, we consider the most obvious candidate for producing offer failures: inadequate developer offers. Table 4 provides a summary of the tender offers by developers. From Table 4, we see that a majority of developer offers fall between the even split solution and the rational Nash solution. However, as predicted by the rational Nash solution, offers are higher in later rounds of negotiations, $0.218,0.266$, and 0.274 , respectively. The average offer of 0.218 in the first negotiations is much higher than the rational solution of 0.148 but lower than the even-split solution of 0.25 . The offer equals or exceeds the even-split offer around $45 \%$ of the time. Moreover, over $85 \%$ of the time, the first offer exceeds the Nash predicted offer. Thus, relative to the Nash prediction developer offers are unaggressive. For the second and third rounds, the average offers by the developer trend up but only to a level slightly above the even-split solution. In the third and last negotiation, the average offer is just slightly above the even-split solution, while $97 \%$ of offers are below the rational Nash prediction. Note that in the last negotiation, previous negotiations payoffs are sunk, and there are at most two remaining moves for each of the players. Thus, in the very subgame where the predictive failure of the rational Nash solution is most pronounced, the backward induction required to solve the game is the simplest. Thus, a simple failure of backward induction and iterated dominance to predict subject strategies in multistage games, as documented by Ochs and Roth [1989] and McKelvey and Palfrey [1992], cannot completely explain the divergence between the rational Nash predictions and our results. 
Having completed our analysis of developer offers, we turn to landowner responses. Our analysis of these responses is initiated in Table 5. In this table, we consider the proportion of offer acceptances and rejections consistent with the predictions of both the Nash and even-split solutions. In the table, NA represents the proportion of offers that are acceptable for the given solution of the game; PA represents the fraction of offers which should be accepted based on the given solution that are actually accepted; and PR represents the fraction of offers which should be rejected that are actually rejected. Perfect predicted success of the equilibrium requires that both PA and PR equal 1 . We see from Table 5 that the even-split offer is accepted roughly $80 \%$ of the time in all rounds. It appears that landowners recognize that they are in stronger bargaining positions in later rounds, and they are less likely to accept even-split offers. On the other hand, there is no clear threshold for offer rejection. Offers below rational offer or even-split offer are not consistently rejected. Thus, in the experiments, developers faced a great deal of uncertainty regarding the landowners' reservation demands.

\section{$<<$ COMP: Place Table 5 about here $>>$}

Next we turn, in Table 6, to consider landowner counteroffers. Each solution to the bargaining game we consider specifies a counteroffer. However, in all solutions, this counteroffer is off the equilibrium path. Thus, our first interesting observation is that, contrary to our theoretical predictions, counteroffers are frequently observed, occurring in 20 of the 172 negotiations. The second observation is that such counteroffers are low relative to the preceding developer offer. Because a rejected developer offer triggers a $\frac{2}{3}$ chance of dissipation, any landowner strategy that involves rejecting a given developer offer and countering with an offer less than thrice the rejected offer is weakly dominated by an otherwise identical strategy of accepting the offer. We call such rejections and counteroffers "weakly disadvantageous." We find that, overall, $95 \%$ of all counteroffers are weakly disadvantageous. As with the developer offers, counteroffers increase with the number of previous negotiations. This increase is consistent with theoretical pre- 
diction of the rational Nash solution. However, the magnitude of the increase is far less than predicted. In fact, the average level of the counteroffer is between the sunk-cost prediction and the even-split prediction, with the sunk-cost model having slightly better predictive power in the last two negotiations and the even-split having higher predictive power in the first negotiation. The divergence from the rational Nash prediction is particularly striking in the last negotiation. The subgame starting with the landowner's counteroffer in the last negotiation is a simple ultimatum game. The mean landowner demand of 0.476 is not only less than the rational value maximizing prediction, 1.00 , it is also much less aggressive than the typical ultimatum games offers. ${ }^{10}$ Binmore et al. [1985] also find that embedding an ultimatum game in a larger game can change subject play in the ultimatum game. However, in their case, embedding increases the degree to which subject behavior fits the rational wealth-maximizing strategic model. In our case, embedding the ultimatum game leads to greater deviation from this model.

\section{$<<$ COMP: Place Table 6 about here $>>$}

In the second and third negotiations, counteroffers also seem low relative to the payoff landowners should be able to extract given the average payoffs to other landowners. Recall that a developer, even one suffering from a sunk-cost bias, should always accept any offer from the landowner that leaves his total payoff positive. The average payoff to a landowner in any negotiation is less than 0.20 . Thus, any demand of 0.60 by the landowner in the first negotiation, should be accepted by the developer if he believes that the subsequent pattern of negotiation will produce payoffs to the next two landowners consistent with the average payoffs in the experiment. Yet, landowner counteroffers of 0.60 and above are almost never observed in the experiment. In short, counteroffers seem very unaggressive, especially when contrasted with landowners' aggressive rejection of developer offers. The unaggressive behavior of the landowners lowers the cost to developers of having their offers rejected, and thus increases developer profits. In the first negotiation however counteroffers were aggressive relative to the Nash 
prediction and in fact all counteroffers were more than the rational Nash solution and less than the sunk cost solution. Given the fairly aggressive pattern of counteroffers in the first negotiation, and subsequent landowner behavior, it is reasonable to conjecture that landowner estimates of payments the developer would make to landowners in subsequent negotiations (which should fix the developer's acceptance threshold in the first negotiation) were less than the payments predicted by the subgame perfect Nash solution.

Finally, we consider developer responses to counteroffers in Table 7, which is structurally identical to Table 5. From the table, we see that in the final round of negotiations all offers were accepted. Because these offers were all less than the sunk cost predicted offer of 0.50 , and a fortiori less than the rational Nash offer 1.0, it is not possible to determine from the data how developers might have responded to a final offer of say 0.60 , which would be close to the typical ultimatum in an ultimatum game played for 1.00 value. Given that such offers were not even attempted, it seems reasonable to conclude that landowners believed that developers would be unwilling to accept such offers. When we turn to the second negotiation, we see that developers are quite aggressive in rejecting counteroffers of more than 0.50 , the optimal rejection threshold in both the sunk cost and rational Nash solutions, rejecting such offers $43 \%$ of the time. However, developers were willing to accept counteroffers in excess of the even split solution, as can be seen from the fact that mean accepted landowner counteroffer is 0.305. Landowner offers are accepted $50 \%$ of the time, with the mean rejected offer equaling 0.339. In short, developers seem willing to grant the landowners, who possess all the bargaining power when making a counteroffer, payoffs in excess of the even split solution but are unwilling to allow a single landowner to capture more than half of the gains from an agreement. 


\subsection{Potential explanations for results}

The game played by experimental subjects is modeled as a game of complete and perfect information. Thus, assuming common knowledge among the players that all players will follow rational value-maximizing strategies, there is no incentive for the subjects to engage in dissipative reputation formation, i.e., to attempt to use proposals or rejections to change the beliefs of the parties with whom they are negotiating. Only in asymmetric information bargaining games do equilibrium solutions typically feature dissipative signaling or reputation formation (see, for example, Grossman and Perry [1986]). However, a number of experimental researchers have pointed out that common knowledge of rationality may be lacking in experimental settings.

The absence of common knowledge of rationality could have two effects on agent behavior (a) because agents do not know the decision rule being followed by other agents, they are uncertain of the reservation demands of other agents in the negotiations. This uncertainty can lead to offer failure which, in sequential negotiations which only yield the economic rent if all negotiations are successful, is very costly. We call this effect "response uncertainty." Second agents who know that other agents are uncertain whether they are Bayes rational may, even if they are Bayes rational, might play strategies that aim to signal to other agents that they are not Bayes rational and thereby profit from changing the best responses of the other agents. We call this effect "signaling." We argue, based both on specific structure of our game and the experimental results, that "response uncertainty" is much more plausible explanation for our results. In our game, a landowner can only signal toughness by rejecting a developer offer and the only opportunity for the landowner to reap a reward from such signaling is through raising the developer's reservation threshold for accepting landowner counteroffers. However, a rational developer's threshold for accepting counteroffers is independent of the developer's beliefs about the toughness of the landowner in the current negotiation and depends rather on the conjectured demands of landowners in prospec- 
tive negotiations. Thus, landowner signaling is a priori rather implausible. Developers signaling by making very low offers in early negotiations is a priori plausible. However, in the experiments very low offers were very infrequent and, in fact, developer offers were on average overly generous. Thus, the signaling probably does not account for our results.

Response uncertainty appears to be a more plausible explanation for the inefficiency of the experimental bargaining. To investigate this the effect of response uncertainty, we estimate a simple structural model of behavior and try to identify the effect of response uncertainty on the outcomes of the experiment. Given the limited number of observations, of necessity, in order to identify preference parameters on which such uncertainty is founded, we are required to impose strong identifying restrictions. One obvious source of uncertainty is uncertainty regarding the decision rule a given agent is following. Agent following different decision rules can be thought of as different agent "types." Because of data limitations, we can only model a limited number of types. Given that the earlier evidence strongly suggests that agents who do not play Bayes rational strategies tend to follow strategies that approximate the even-split strategy, our empirical model incorporates two agent types-Bayes rational, and even-split. Introducing these two types generates "type uncertainty." Although even-split and Bayes rational strategies roughly correspond to typical offers, most offers were not perfectly consistent with either Bayes rational or even-split behavior. Thus, even if an agent perfectly identified other agents' type, that agent could not predict other agents' decisions certainty. To incorporate uncertain responses given type, which we call "typeconditioned uncertainty," as well as type uncertainty, we employ the following stylized but parsimonious empirical parameterization. Let $\tilde{R}_{t}^{a}, a \in\{$ Developer,Landowner $\}$, $t \in\{$ Rational,Even-split $\}$ represent the reservation demands of landowners and developers conditioned on their type, which is assumed to be either rational Bayesian (Rational) or even-split (Even split). Similarly let $\tilde{O}_{t}^{a}$ represent the offers made by landowners 
and developers. We assume that

$$
\begin{aligned}
& \tilde{R}_{t}^{a}=r_{t}^{a}\left(1+\sigma \tilde{z}_{t}^{a}\right), \quad \tilde{z}_{t}^{a} \stackrel{\text { dist. }}{=} \operatorname{Normal}[0,1] \\
& \tilde{O}_{t}^{a}=o_{t}^{a}\left(1+\sigma \tilde{w}_{t}^{a}\right), \quad \tilde{w}_{t}^{a} \stackrel{\text { dist. }}{=} \operatorname{Normal}[0,1]
\end{aligned}
$$

where the standard normal variates, $\tilde{w}_{t}^{a}$ and $\tilde{z}_{t}^{a}$ are jointly independent. $o_{t}^{a}\left(r_{t}^{a}\right)$ represents the predicted offer (reservation) price of a type $t$ agent. The predicted behavior for a Bayes rational agent is given by the analysis in Section 2.2. The predicted behavior of an even-split agent is $o=r=1 /(n+1)$. Landowner accept offers from developers that at least equal $R$. Developers accept counteroffers by landowners which are no greater than $R$. Using this parameterization, type-conditioned uncertainty is represented by $\sigma$. To introduce uncertainty concerning type, we estimate the fraction $\alpha \in(0,1)$, which represents the fraction of agents that follow the even split strategy. The model is estimated using the maximum likelihood method.

Table 8 shows the results from this maximum likelihood estimates. The estimate of the fraction of even-split players, $\alpha$, is 0.685 , indicating that a large fraction of the players are even-split players. The estimate of $\sigma$ is 0.274 . This shows that the variation is quite large. The maximum likelihood tests indicate that a significant degree of preference heterogeneity. Both preference heterogeneity and type-conditioned uncertainty are required to rationalize our results. The fairly high estimated fraction of players who are even-split types rationalizes the fairly "unaggressive" offers and counteroffers observed in the experiment—developer offers to landowners usually exceeded the rational Nash offer and counteroffers to developers were much lower than the rational Nash counteroffer. If in fact, a large fraction of players are even-split types, then aggressive offers will trigger rejection. Thus, in such an environment, even a rational Nash type will moderate his offers. However, the presence of even split players per se cannot explain offer failure. To see this note that if $\alpha \approx 1$ and $\sigma \approx 0$, then the equilibrium will call for rational Nash players to make even split offers. Such offers will be accepted with probability close to 1 and the solution to the game will be quite efficient. However when 
$\sigma$ is large, the marginal cost, in terms of offer rejection from demanding more than the even-split solution will be attenuated and rational types will thus have an incentive to make offers which might trigger rejection. At the same time, type-conditioned preference uncertainty, alone, cannot explain the unaggressive offer pattern. To see this, note that as type-conditioned uncertainty grows, the marginal effect of the size of an agents demands on the probability that the demands will be accepted falls. This leads to more, not less aggressive offers. In order to fit the two pervasive features of the results-unaggressive offers and a high probability of failure-both type heterogeneity and type-conditioned uncertainty are required. Thus, the results of the maximum likelihood estimation, which finds strong evidence for both, should not be too surprising. ${ }^{11}$

\section{$<<$ COMP: Place Table 8 about here $>>$}

\section{Outcomes of the TC-O game}

\subsection{Basic results}

We conducted 60 games with TC-O mechanism. 39 of these games, 65\%, succeed without any inefficient dissipation. This success rate is much higher that the success rate in SC-P games, 41\%. Table 9 Panel A presents the payoff for the developer and landowners in all TC-O games and in all successful TC-O games. On average, the developer captures close to $25 \%$ of the surplus and the landowners collectively capture around $40 \%, 35 \%$ is dissipated. In fact, the ratio between average developer and landowner surplus capture is within the rather narrow range of surplus divisions supported by subgame perfect Nash equilibria of TC-O. The major deviation from the equilibrium predicted surplus allocations in the TC-O is inefficiency losses which are still high, although much lower than in the SC-P. In fact, conditioned on an efficient solution being reached, the observed average surplus division, $38 \%$ to the developer, is within the range of surplus allocations to the developer, $37 \%-40 \%$ that can be supported by 
subgame perfect Nash equilibria.

Table 9 Panel B presents the offers made by the developer in the initial tender offer phase. The average of all 180 offers in the tender offer phase is $14.9 \%$, well below the minimum rationalizable offer. The developers make the same offer to all three land owners in 33 of the 60 games. The average offer in same-offer games is $12.9 \%$ and the average offer in the different-offer games is higher, $17.3 \%$. In the sequential phase shown in Panel C, we aggregate negotiations based on how many negotiations remaining using the variables NR2, NR1 and NR0. A negotiation is aggregated into $\mathrm{NR} i$ if there are $i$ remaining negotiations which must be successfully concluded for the property transfer to occur. Although our analysis shows that the number of remaining negotiations should be positively associated with developer offers, the association is negative in the experiments. For example, the average developer offer for NR2 negotiations is $17.9 \%$, while the average for NR0 negotiations is $21.1 \%$. No developer offers more than the rational equilibrium offer $\left(\frac{1}{3}\right.$ of the residual value) when there is either one landowner or two landowners remaining to be negotiated. In contrast, in the final negotiation when there is no landowner to be negotiated, $75 \%$ of the offers are above the rational equilibrium offers. Moreover, NR2 and NR1 contain one offer each that exceeds the even-split of $25 \%$, while NR0 contains six such offers.

\section{$<<$ COMP: Place Table 9 about here $>>$}

Table 10 summarizes the acceptance decision of the landowners. In the initial tender-offer phase, a majority of offers $(80.6 \%)$ are rejected. The average rejected offer is $14.2 \%$; the average accepted offer is $17.8 \%$. About $21 \%$ of offers are equal or above the symmetric Nash equilibrium offer of $20 \%$, and $44.7 \%$ of such offers are accepted. $87 \%$ of the remaining offers are rejected. None of the tender offers equals or exceeds the even-split level of $25 \%$. On average, developers made low offers in the initial tender offer phase and these offers are typically rejected. In the sequential continuation phase, developers offer more than in the initial tender offer phase, which is consistent with the 
Goswami

Nash best-reply behavior, and increase their offers as the game progresses through the sequential negotiations, which is not consistent with Nash best-reply behavior.

\section{$<<$ COMP: Place Table 10 about here $>>$}

\subsection{Potential explanations for results}

Developers frequently appear to use the initial tender-offer phase to exploit naive landowners. For example, $10 \%$ of the tender offers are less than $5 \%$, and about $30 \%$ of the offers are less than $15 \%$. This strategy is moderately effective: out of the twenty offers below $5 \%, 5 \%$ were accepted. $10 \%$ of the offers below $15 \%$ are accepted. However, it is not clear if this strategy is optimal even in the presences of some naive landowners. As the solution to the TC-O mechanism developed in Section 3.2 shows, developer payoffs in subgames in which landowners hold out are lower than the developer's payoff when all landowners accept optimal tender offers. Acceptance of the tender offer by one landowner commits value to that landowner and thus has a positive externality. From the developer's perspective, taking value "off-the-table" in subsequent negotiations reduces the reservation demands of other landowners. Thus, making low offers that are likely to be rejected by rational landowners is costly and perhaps developers did not factor in this cost when fixing their tender offers. Or perhaps they believe that the probability that the landowners are naive is so large that this cost is more than compensated by the benefit of "fishing" for naive landowners.

Turning to landowner responses, in Table 11, we use logistic regressions to study which factors contribute to the landowners' accept/reject decision. Panel A is for initial tender offer phase, and Panel B is for continuation phase. We first consider symmetric tender offers. First, We regress acceptance decision on OFFER, a variable representing the level of the developer's tender offer. Next, we include an aditional dummy variable, RATIONAL, which equals one if the offer is equal to or above the symmetric Nash equilibrium offer of $20 \%$. We see the coefficient for OFFER is positive and 
highly significant in the first regression. This shows that landowners take offer level into consideration for their acceptance decision. Note that after the RATIONAL dummy is included, the only significant coefficient is for the RATIONAL dummy. This shows that landowners respond to the offer level in a nonlinear fashion, accepting with high probability as long as the offer at least equals the symmetric Nash equilibrium tender offer. This non-linear response is consistent with best response behavior because accepting an offer if and only if it exceeds $20 \%$ is the equilibrium landowner response in a Nash symmetric equilibrium. Thus, while developer offers are for the most part too low to be consistent with equilibrium predictions in the initial tender offer phase, landowner responses in the initial tender offer phase are much more consistent.

When developers make asymmetric tender offers, we find that our models have much less predictive power. Given different landowners receive different tender offers, we can consider the effect of offer asymmetry. We use the variable MAX, which equals one if no landowner received a higher tender offer. For asymmetric offers, we report two regression results: One with OFFER only, and one with OFFER and MAX. While OFFER is marginally significant by itself, the significance goes to MAX when MAX is included. In unreported work, We also run regression with OFFER and RATIONAL, but RATIONAL is not significant. On possible interpretation of this result, is that landowners, who are ex ante symmetric, believe that asymmetric tender offers are unfair and thus reject such offers even if in absolute terms the offers are not particularly low. We next combine all tender offers and report two regressions. The first one includes OFFER, RATIONAL and MAX. In this case, only RATIONAL is significant. The second regression includes two variables, MEANOFFER and DIFFMEAN. MEANOFFER is the average of the three tender offers, and DIFFMEAN is the difference between the tender offer and MEANOFFER. The aim of this regression is to capture both the overall offer level and its asymmetry. As shown in the table, only MEANOFFER is positive and significant. DIFFMEAN is positive but insignificant.

In Table 11 Panel B, we present the results for the offers in the continuation phase. 
The first regression includes OFFER, the level of the offer, the dummy variable MAX which equals to one if the offer is no lower than any of the tender offers and previous sequential offers. The motivation for this variable is that a landowner might refuse to accept an offer that is less than previous offers. We run this regression separately for NR2, NR1 and NR0. OFFER is significantly positive in NR2 and NR1, but MAX is insignificant in all regressions. In the next regression, we include OFFER and the dummy variable RATIONAL, which equals one if the offer at least equals the minimum offer in any Nash equilibrium. We only run this regression for NR0 because there are no offers that clear the rational lower bound in NR2 or NR1. In this case, none of the variables is significant although the sign of OFFER is in the predicted positive direction. Finally, we run two regressions using all offers in the continuation phase. The first includes OFFER, MAX and RATIONAL. The second replaces RATIONAL with RESIDUAL, the residual value when the developer makes the offer, since the rational offer is $\frac{1}{3}$ of RESIDUAL. In both regressions, only OFFER is positive and significant. Other variables are insignificant.

\section{$<<$ COMP: Place Table 11 about here $>>$}

In summary, landowner responses to symmetric developer tender offers are fairly consistent with the Nash equilibrium prediction. Developer offers were significantly lower, on average, than predicted and landowner and developer actions in the sequential negotiations are less consistent with equilibrium predicted behavior. The most salient deviation from the Nash prediction was the low average level of developer offers. Deviations from equilibrium behavior result large inefficiencies relative to efficient equilibrium outcomes. However, conditioned on an efficient agreement being reached, the average division of the surplus between the developer and landowners is in the narrow range of surplus divisions supportable by Nash equilibria. Moreover, the overall level of inefficiency was much less than under the SC-P mechanism. 


\section{Conclusions}

The first and most obvious conclusion form our results is that, even in perfect settings, bargaining efficiency is problematic and dependent on negotiation mechanisms, even when the equilibrium solutions of the mechanisms are equally efficient. This observation suggests that specific bargaining mechanisms matter for attaining efficient outcomes but not for the reasons suggested in the classical implementation literature. Our first game, SC-P, was a game of perfect information with a unique subgame perfect equilibrium. The outcome of this equilibrium was fully efficient. However, when implemented in the laboratory it produced extremely inefficient bargaining and virtually eliminated the gain from initiating value increasing property-right transfers. In contrast, the TC-O game, designed to overcome behavioral obstacles to efficient contracting, was a game of imperfect information with multiple equilibria. Yet when deployed in the laboratory, it produced far more efficient bargaining. Thus, real-world investment in costly legal technology and costly structured bargaining mechanisms may not be motivated by the need to overcome asymmetric information or moral hazard problems but rather be evolutionary adaption to behavioral biases. ${ }^{12}$

Second, our results provide a rationale for investing resources in designing new negotiation and contracting mechanisms and empirically validating the efficiency of standard contracts and structured negotiation procedures. Legal innovation can increase bargaining efficiency even in the absence of "market imperfections" such as moral hazard and asymmetric information. Thus, our analysis predicts that rather complex legal mechanisms will evolve for handling value-increasing property rights reallocations which involve multiple parties even when the parties are all equally well informed about the surplus generated.

Third, our results suggest why private negotiations fail. In our experiments, the key driver of negotiation failure appears to be lack of common knowledge of rationality and preferences of other agents. This driver has first-order importance even in a labora- 
tory setting were the experimenter endows agents with clear and transparent rewards and structures the bargaining problem in a very stylized and simple fashion. While agent irrationality can produce failure under any bargaining mechanism, mechanisms vary with respect to the degree to which rational agents optimal strategies are dependent on their estimates of the rationality of other agents and with respect to the costs rational agents must bear to adjust their demands to accommodate the irrationality of other agents. Thus reducing the dependence of rational best responses on conjectured behavior of other agents and increasing the action space in a way that permits rational agents to make offers that simultaneously satisfy the reservation demands both of other rational agents and agents with fairness and/or rank-based preferences should generally increase efficiency. 


\section{Notes}

${ }^{1}$ For example, see [Rubinstein, 1985].

${ }^{2}$ See, for example Cooter [1982] and Furusawa and Wen [2003]

${ }^{3}$ Both the law and the legal literature on insolvency has drawn a sharp distinction between executory and non-executory contracts. For example in U.S. insolvency law, a debtor-in-possession (or a bankruptcy trustee) has the right to decide whether to perform contractual obligations under an executory contract ("assuming the contract") or refuse to perform ("rejecting the contract")[Countryman, 1972].

${ }^{4}$ Hobbes [1983, Chapt. II-X] argues that, in the state of nature, agreements become enforceable as soon as one party performs on the agreement. Until such time, either party can justly repudiate the agreement because, absent an enforcement system, each party can legitimately doubt whether the other party will ever perform. In our setting, the developer paying the agreed purchase price constitutes performance and would obligate a self-interested but prudent Hobbsian landowner to surrender title.

${ }^{5}$ I.e., the sequential cash purchase game is a game of perfect information. The game has a unique sub-game perfect equilibria that produces an efficient outcome. In fact, the subgame perfect equilibrium equals the unique strategy that remains after the elimination of weakly dominated strategies.

${ }^{6}$ For example, Gomes [2005] consider contracts that may impose externalities on other agents. Genicot and Ray [2006] show that, in the presence of externalities, multiagent negotiations may fail. Caruana et al. [2007] model the effect of exogenous deadlines. Marx and Shaffer [2010] consider sequential negotiations with breakup fees; Horn and Wolinsky [1988] consider the effect of coalition formation; Cai [2000] considers the effect of allowing agents who fail to reach agreement in one negotiation to reenter negotiations at a later date; Noe and Wang [2004] consider sequential negotiations when the outcomes of earlier negotiations are unknown to parties later in the sequence.

${ }^{7}$ See also Croson and Johnston [2000] and Aivazian et al. [2009] for similar collec- 
tive decision experiments.

8 After obtaining permission from Institutional Review Board and following the Board's requirement, we have put advertisements in both graduate and undergraduate business schools in two different locations to look for potential subjects.

${ }^{9}$ See the online supplement for the instruction sheet, decision tree, and computer screen shots.

${ }^{10}$ See Camerer [2003] for a survey of the results of ultimatum experiments.

${ }^{11}$ One limitation related to the normal distribution assumption of uncertainty in the empirical model is that reservation values less than 0 or greater than 1 and offers less than 0 or greater than 1 are possible. This is particularly a problem for counteroffers in the second and third negotiations, where the predicted rational Nash counteroffer is one or close to one. For this reason, as well as estimating the model for all decisions, we also estimated the model excluding counteroffers and developer replies to counteroffers. The estimated parameters in the restricted model and the unrestricted model are quite similar.

${ }^{12}$ For an example of costly mechanisms that restrict the order and timing of agent moves, see Betker [1997] for an analysis of Chapter 11 bankruptcy costs. 


\section{References}

Varouj Aivazian, Jeffrey Callen, and Susan McCracken. Experimental tests of core theory and the coase theorem: Inefficiency and cycling. Journal of Law and Economics, 52:745-759, 2009.

David P. Baron and Bengt Holmström. The investment banking contract for new issues under asymmetric information: Delegation and the incentive problem. The Journal of Finance, 35(5):1115-1138, 1980.

Elazar Berkovitch, Ronen Israel, and Jaime F. Zender. The design of bankruptcy law: A case for management bias in bankruptcy reorganizations. Journal of Financial and Quantitative Analysis, 33:441-464, 1998.

Brian L. Betker. Financial Management, 26(4):56-68, 1997.

Kenneth Binmore, Avnner Shaked, and John Sutton. Testing noncooperative bargaining theory: A preliminary study. American Economic Review, 75:1175-1180, 1985.

Hongbin Cai. Delay in multilateral bargaining under complete information. Journal of Economic Theory, 93(2):260-276, 2000.

Colin Camerer. Behavioral Game Theory. Princeton University Press, 2003.

Guillermo Caruana, Liran Einav, and Daniel Quint. Multilateral bargaining with concession costs. Journal of Economic Theory, 132:147-166, 2007.

Sean Collins and Mark Isaac. Holdout: Existence, information, and contingent contracting. Journal of Law and Economics, 55:793-814, 2012.

Robert Cooter. The cost of coase. The Journal of Legal Studies, 11(1):1-33, 1982.

Vern Countryman. Executory contracts in bankruptcy: Part i. Minnesota Law Review, $57: 439-492,1972$. 
Rachel Croson and Jason Johnston. Experimental results on bargaining under alternative property rights regimes. Journal of Law, Economics, and Organization, 16: $50-73,2000$.

Taiji Furusawa and Quan Wen. Bargaining with stochastic disagreement payoffs. International Journal of Game Theory, 31(4):571-591, 2003.

Garance Genicot and Debraj Ray. Contracts and externalities: How things fall apart. Journal of Economic Theory, 131:71-100, 2006.

Armando Gomes. Multilateral contracting with externalities. Econometrica, 73:1329_ $1350,2005$.

Sanford Grossman and Motty Perry. Sequential bargaining under asymmetric information. Journal of Economic Theory, 39:120-154, 1986.

Thomas Hobbes. De Cive. Clarendon Press: Oxford University, 1983.

Elizabeth Hoffman and Matthew Spitzer. The coase theorem: Some experimental tests. Journal of Law and Economics, 25:73-98, 1982.

Henrik Horn and Asher Wolinsky. Worker substitutability and patterns of unionisation. Economic Journal, 98(127):484-97, 1988.

Daniel Kahneman, Jack Knetsch, and Richard Thaler. Experimental tests of the endowment effect and the coase theorem. Journal of Political Economy, 98:1325-1348, 1990.

Leslie Marx and Greg Shaffer. Break fees and bargaining power in sequential contracting. International Journal of Industrial Organization, 28:451-463, 2010.

R. Preston McAfee and Marius Schwartz. Opportunism in multilateral vertical contracting: Nondiscrimination, exclusivity and uniformity. American Economic Review, 84: 210-230, 1994. 
Richard McKelvey and Thomas Palfrey. A experimental study of the centipede game. Econometrica, 60:803-836, 1992.

Thomas Noe and Jun Wang. Fooling all of the people some of the time: A theory of endogenous sequencing in confidential negotiations. Review of Economic Studies, $71: 855-881,2004$.

Jack Ochs and Alvin Roth. A experimental study of sequential bargaining. American Economic Review, 79:355-384, 1989.

Martin Osborne and Ariel Rubinstein. Bargaining and Markets. Academic Press, New York, NY, 1990.

Alvin Roth and Michael Malouf. Game-theoretic models and the role of information in bargaining. Psychological Review, 86:574-594, 1979.

Ariel Rubinstein. A bargaining model with incomplete information about time preferences. Econometrica, 53(5):1151-1172, 1985. 
Goswami

\section{Tables}

Table 1: Summary of Game Design

This table presents the summary of our game design. A, B, and C are all SC-P games. A represents the game with 1 developer and 1 land owner; $\mathrm{B}$ represents the game with 1 developer and 2 land owners; $\mathrm{C}$ represents the game with 1 developer and 3 land owners. D is TC-O game with 1 developer and 3 land owners.

\begin{tabular}{|c|c|c|c|c|}
\hline \multicolumn{5}{|c|}{ Game Design by Session } \\
\hline Session & $\begin{array}{c}\text { No. of } \\
\text { Participants }\end{array}$ & $\begin{array}{l}\text { Game } \\
\text { Design }\end{array}$ & Sequence & $\begin{array}{l}\text { Practice } \\
\text { Rounds }\end{array}$ \\
\hline 1 & 12 & B-A-B & $\mathrm{B} \times 4 \rightarrow \mathrm{A} \times 4 \rightarrow \mathrm{B} \times 12$ & first 4 \\
\hline 2 & 12 & A-B-A & $\mathrm{A} \times 4 \rightarrow \mathrm{B} \times 9 \rightarrow \mathrm{A} \times 4 \rightarrow \mathrm{B} \times 3$ & first 4 \\
\hline 3 & 12 & A-C-A & $\mathrm{A} \times 4 \rightarrow \mathrm{C} \times 12 \rightarrow \mathrm{A} \times 4 \rightarrow \mathrm{C} \times 3$ & first 4 \\
\hline 4 & 12 & C-A-C & $\mathrm{C} \times 4 \rightarrow \mathrm{A} \times 4 \rightarrow \mathrm{C} \times 12$ & first 4 \\
\hline 5 & 16 & $\mathrm{D}$ & $\mathrm{D} \times 19$ & first 4 \\
\hline \multicolumn{5}{|c|}{ Game Design by Treatment } \\
\hline $\begin{array}{l}\text { Game } \\
\text { Type }\end{array}$ & $\begin{array}{l}\text { Practice } \\
\text { Rounds }\end{array}$ & $\begin{array}{l}\text { No. of } \\
\text { Rounds }\end{array}$ & $\begin{array}{c}\text { No. of Groups } \\
\text { per Round }\end{array}$ & $\begin{array}{l}\text { No. of } \\
\text { Games }\end{array}$ \\
\hline $\mathrm{A}$ & 8 & 16 & 6 & 96 \\
\hline B & 4 & 24 & 4 & 96 \\
\hline $\mathrm{C}$ & 4 & 27 & 3 & 81 \\
\hline $\mathrm{D}$ & 4 & 15 & 4 & 60 \\
\hline
\end{tabular}

Table 2: Summary of Negotiation Success in SC-P Games This table presents the number of bilateral negotiations $(\mathrm{N})$, successful ones (N Success), failed ones (N Failure), and percent of failed negotiations (\% Failure). N1, N2, and $\mathrm{N} 3$ represent the first, second, and third negotiation, respectively.

\begin{tabular}{lcccc}
\hline & N & N Success & N Failure & \% Failure \\
\hline N1 & 81 & 52 & 29 & $36 \%$ \\
N2 & 52 & 39 & 13 & $25 \%$ \\
N3 & 39 & 33 & 6 & $15 \%$ \\
ALL & 81 & 33 & 48 & $59 \%$ \\
\hline
\end{tabular}


Table 3: Payoffs in SC-P Games

This table presents the means and standard deviations of the payoffs received by the developer and landowners in three negotiations in all games and all successful games. This table also presents the predicted payoffs in rational value-maximizing equilibrium and sunk-cost/even-split equibrium.

\begin{tabular}{|c|c|c|c|c|c|c|c|}
\hline & \multicolumn{2}{|c|}{ All Games } & \multicolumn{2}{|c|}{ Successful Games } & \multirow{2}{*}{$\begin{array}{c}\text { Rational } \\
\text { Equil. }\end{array}$} & \multirow{2}{*}{$\begin{array}{c}\text { Sunk-cost } \\
\text { Equil. }\end{array}$} & \multirow[t]{2}{*}{ Even-split } \\
\hline & Mean & StdDev & Mean & StdDev & & & \\
\hline Developer & -0.011 & 0.218 & 0.174 & 0.065 & 0.296 & 0.400 & 0.250 \\
\hline Landowner 1 & 0.169 & 0.130 & 0.263 & 0.041 & 0.148 & 0.200 & 0.250 \\
\hline Landowner 2 & 0.133 & 0.140 & 0.279 & 0.022 & 0.222 & 0.200 & 0.250 \\
\hline Landowner 3 & 0.116 & 0.143 & 0.284 & 0.043 & 0.333 & 0.200 & 0.250 \\
\hline
\end{tabular}

Table 4: Initial Offers in SC-P Games

This table presents the number $(\mathrm{N})$ and average of initial offers made by the developer. Standard deviations are in paratheses. The table also presents comparison of the initial offers with predicted strategies in rational value-maximizing equilibrium and even-split equilibrium. For each equilibrium, the table includes the predicted offer (Strategy), the average of absolute errors between initial offers and predicted strategy (AbsErr) and its standard deviation in paratheses, and the percent of initial offers that are acceptable based on the equilibrium (NA). The table also presents the number and percent of initial offers that are between the predicted strategies of two equilibria.

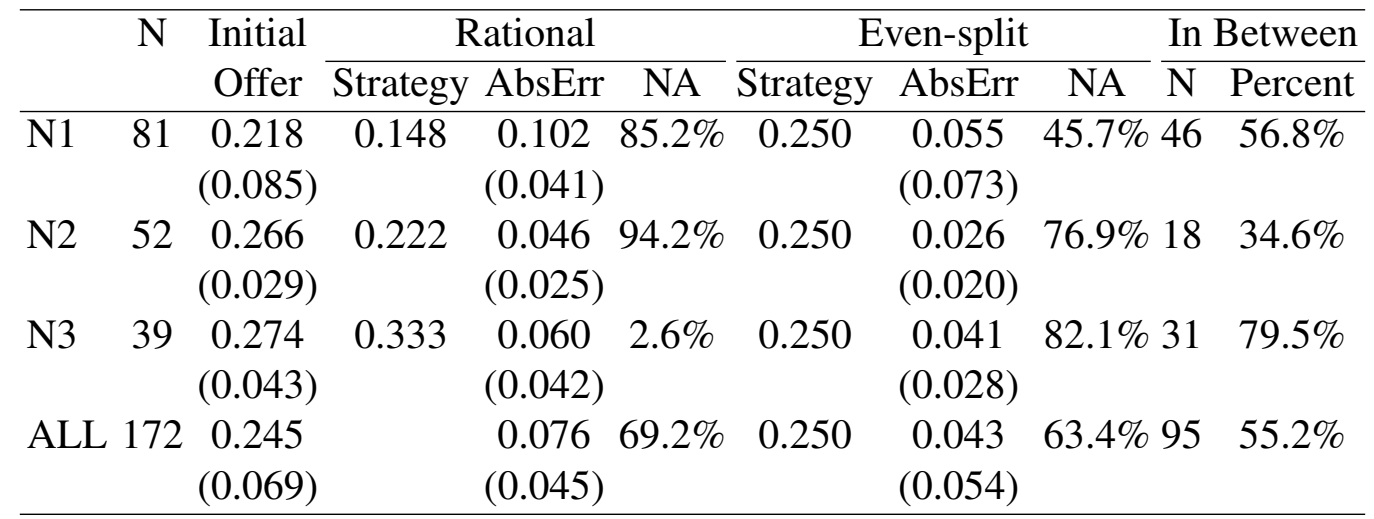


Goswami

Table 5: Acceptance Decision of Initial Offers in SC-P Games

This table presents the number $(\mathrm{N})$, average (Mean), and standard deviation (in paratheses) of initial offers that are accepted and rejected. The table also presents the percent of acceptable offers (NA) based on two equilibria, rational value-maximizing equilibrium and even-split equilibrium. In addition, it provides the percent of acceptable offers based on the equilibrium that are accepted (PA), and percent of rejectable offers based on the equilibrium that are rejected (PR).

\begin{tabular}{|c|c|c|c|c|c|c|c|c|c|c|}
\hline & \multicolumn{2}{|c|}{ Accepted } & \multicolumn{2}{|c|}{ Rejected } & \multicolumn{3}{|c|}{ Rational } & \multicolumn{3}{|c|}{ Even-split } \\
\hline & $\mathrm{N}$ & Mean & $\mathrm{N}$ & Mean & NA & PA & PR & NA & PA & PR \\
\hline N1 & 48 & $\begin{array}{c}0.260 \\
(0.037)\end{array}$ & 33 & $\begin{array}{c}0.156 \\
(0.098)\end{array}$ & $85.2 \%$ & $69.6 \%$ & $100.0 \%$ & $45.7 \%$ & $83.8 \%$ & $61.4 \%$ \\
\hline $\mathrm{N} 2$ & 36 & $\begin{array}{c}0.275 \\
(0.026)\end{array}$ & 16 & $\begin{array}{c}0.246 \\
(0.027)\end{array}$ & $94.2 \%$ & $71.4 \%$ & $66.7 \%$ & $76.9 \%$ & $82.5 \%$ & $75.0 \%$ \\
\hline N3 & 30 & $\begin{array}{c}0.280 \\
(0.043)\end{array}$ & 9 & $\begin{array}{c}0.253 \\
(0.039)\end{array}$ & $2.6 \%$ & $100.0 \%$ & $23.7 \%$ & $82.1 \%$ & $81.3 \%$ & $42.9 \%$ \\
\hline ALL & 114 & $\begin{array}{c}0.270 \\
(0.036)\end{array}$ & 58 & $\begin{array}{c}0.196 \\
(0.089)\end{array}$ & $69.2 \%$ & $70.6 \%$ & $43.4 \%$ & $63.4 \%$ & $82.6 \%$ & $61.9 \%$ \\
\hline
\end{tabular}

Table 6: Analysis of Counteroffers by Landowners in SC-P Games

This table presents the number $(\mathrm{N})$, average (Mean), and standard deviation (in paratheses) of counteroffers made by landowners. The table also provides the average absolute errors of counteroffers from equilibrium strategies of rational value-maximizing equilibrium, sunk-cost equilibrium, and even-split equilibrium. The standard deviations of absolute errors are in paratheses. It also presents the percent of counteroffers that are weakly disadvangeous (Disadv. Offers), that is, counteroffers that are less than or equal to three times the initial offers.

\begin{tabular}{ccccccc}
\hline & N Counter & \multicolumn{4}{c}{ AbsErr } & Disadv. \\
\cline { 4 - 6 } & & Offer & \multicolumn{2}{c}{ Rational Sunk-cost Even-split } & Offers \\
\hline $\mathrm{N} 1$ & 12 & 0.312 & 0.133 & 0.288 & 0.062 & $83.3 \%$ \\
& & $(0.046)$ & $(0.046)$ & $(0.046)$ & $(0.046)$ & \\
$\mathrm{N} 2$ & 4 & 0.313 & 0.354 & 0.288 & 0.063 & $100.0 \%$ \\
& & $(0.025)$ & $(0.025)$ & $(0.025)$ & $(0.025)$ & \\
$\mathrm{N} 3$ & 4 & 0.363 & 0.638 & 0.238 & 0.113 & $100.0 \%$ \\
& & $(0.096)$ & $(0.096)$ & $(0.096)$ & $(0.096)$ & \\
ALL & 20 & 0.322 & 0.278 & 0.278 & 0.072 & $90.0 \%$ \\
& & $(0.057)$ & $(0.211)$ & $(0.057)$ & $(0.057)$ & \\
\hline
\end{tabular}


Table 7: Acceptance Decision of the Developer in SC-P Games

This table presents the number $(\mathrm{N})$, average (Mean), and standard deviation (in paratheses) of counteroffers that are accepted and rejected. The table also presents the percent of acceptable counteroffers (NA) based on two equilibria, rational equilibrium and sunk-cost equilibrium. In addition, it provides the percent of acceptable offers based on the equilibrium that are accepted (PA), and percent of rejectable offers based on the equilibrium that are rejected (PR).

\begin{tabular}{|c|c|c|c|c|c|c|c|c|c|c|}
\hline & \multicolumn{2}{|c|}{ Accepted } & \multicolumn{2}{|r|}{ Rejected } & \multicolumn{3}{|c|}{ Rational } & \multicolumn{3}{|c|}{ Even-split } \\
\hline & $\mathrm{N}$ & Mean & $\mathrm{N}$ & Mean & NA & PA & PR & NA & PA & PR \\
\hline N1 & 4 & $\begin{array}{c}0.300 \\
(0.016)\end{array}$ & 8 & $\begin{array}{c}0.318 \\
(0.056)\end{array}$ & $100.0 \%$ & $33.3 \%$ & - & $0.0 \%$ & - & $66.7 \%$ \\
\hline $\mathrm{N} 2$ & 3 & $\begin{array}{r}0.300 \\
(0.000)\end{array}$ & 1 & $\begin{array}{c}0.350 \\
-\end{array}$ & $100.0 \%$ & $75.0 \%$ & - & $0.0 \%$ & - & $25.0 \%$ \\
\hline N3 & 3 & $\begin{array}{r}0.317 \\
(0.035)\end{array}$ & 1 & $\begin{array}{c}0.500 \\
-\end{array}$ & $100.0 \%$ & $75.0 \%$ & - & $0.0 \%$ & - & $25.0 \%$ \\
\hline ALI & & $\begin{array}{c}0.305 \\
(0.021)\end{array}$ & 10 & $\begin{array}{c}0.339 \\
(0.076)\end{array}$ & $100.0 \%$ & $50.0 \%$ & - & $0.0 \%$ & - & $50.0 \%$ \\
\hline
\end{tabular}

Table 8: Maximum Likelihood Estimates in SC-P Games

This table presents the maximum likelihood estimates of landowner and developer offers and offer responses assuming the agents play random responses drawn from a mixture of offer/response distributions centered on two types of responses: rational Nash and even-split. The parameter $\alpha$ represents the estimated probability of drawing from the even-split distribution. The parameter $\sigma$ represents the variance of actions conditioned on type of response.

\begin{tabular}{lcc}
\hline & Parameter & Standard \\
& Estimate & Error \\
\hline$\alpha$ & 0.685 & 0.036 \\
$\sigma$ & 0.274 & 0.010 \\
Nobs & 471 & \\
LogL & -387.4 & \\
\hline
\end{tabular}


Table 9: Payoffs and Offers by the Developer in TC-O games

Panel A presents the means and standard deviations of the payoffs received by the developer and landowners in all games and all successful games. Panel B presents the number $(\mathrm{N})$ and average of initial simultaneous offers made by the developer. Panel $\mathrm{C}$ also presents the number $(\mathrm{N})$ of games that the developer makes the same simultaneous offers and its offer average, and the number of games that the developer makes unequal simultaneous offers and its offer average. Panel $\mathrm{C}$ presents the number $(\mathrm{N})$ and average of initial offers in the sequential negotiations made by the developer. Standard deviations are in paratheses. Panel B also presents comparison of the initial offers with predicted strategies in rational value-maximizing equilibrium and even-split equibrium. For each equilibrium, the table includes the predicted offer (Strategy), the average of absolute errors between initial offers and predicted strategy (AbsErr) and its standard deviation in paratheses, and the percent of initial offers that are acceptable based on the equilibrium (NA). The table also presents the number and percent of initial offers that are between the predicted strategies of two equilibria.

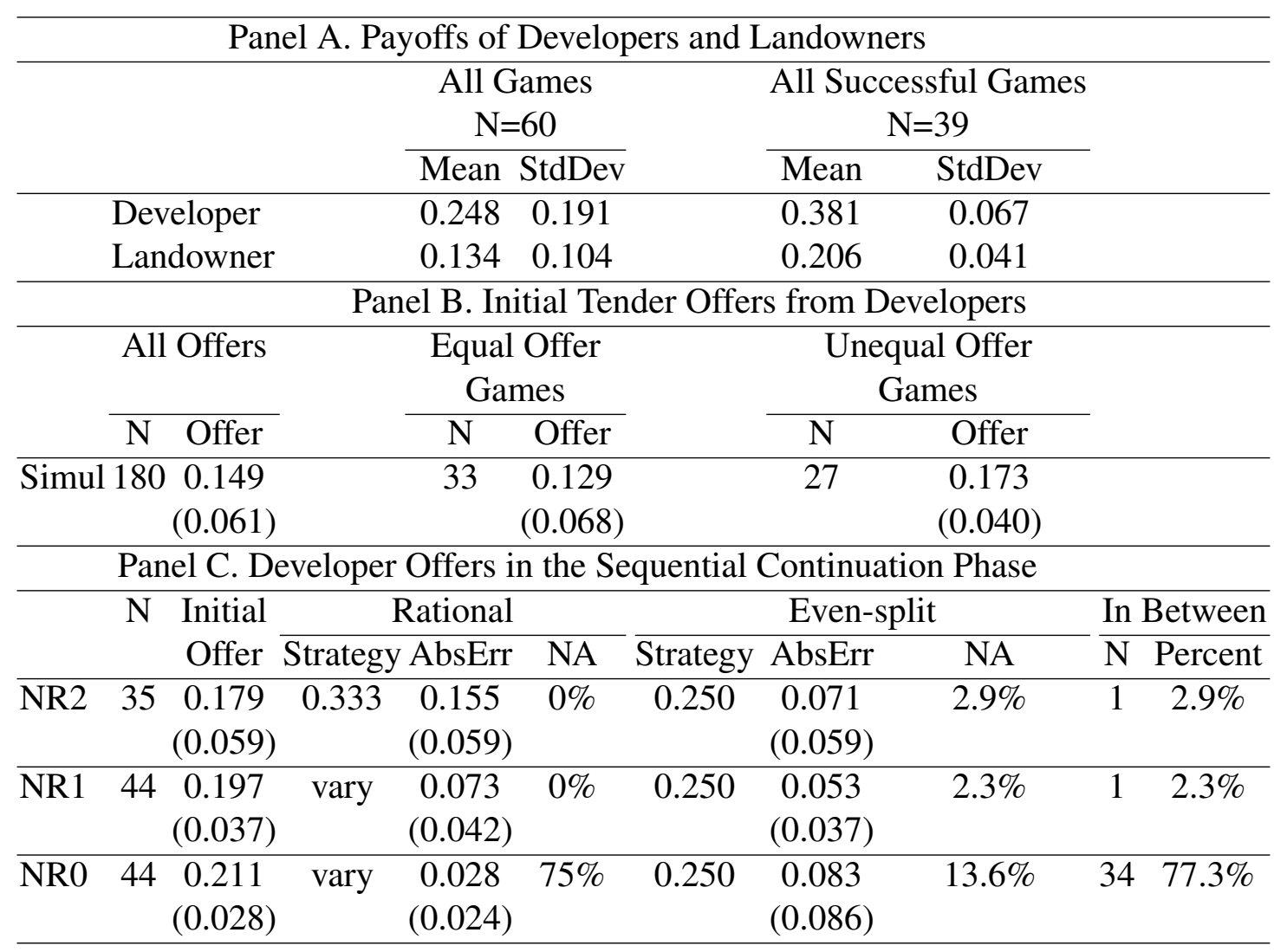


Table 10: Acceptance Decision of Landowners in TC-O Games

This table presents the number $(\mathrm{N})$, average (Mean), and standard deviation (in paratheses) of initial offers (in both the tender offer phase and the sequential continuation phase) that are accepted and rejected. The table also presents the percent of acceptable offers (NA) based on two equilibria, rational value-maximizing equilibrium and evensplit equilibrium. In addition, it provides the percent of acceptable offers based on the equilibrium that are accepted (PA), and percent of rejectable offers based on the equilibrium that are rejected (PR). For simultaneous offers, we use the symmetric equilibrium offer of 0.2 as the rational equilibrium offer.

\begin{tabular}{|c|c|c|c|c|c|c|c|c|c|c|}
\hline & \multicolumn{2}{|c|}{ Accepted } & \multicolumn{2}{|c|}{ Rejected } & \multicolumn{3}{|c|}{ Rational } & \multicolumn{3}{|c|}{ Even-split } \\
\hline & $\mathrm{N}$ & Mean & $\mathrm{N}$ & Mean & NA & PA & PR & NA & PA & PR \\
\hline \multirow[t]{2}{*}{ Simul } & 35 & 0.178 & 145 & 0.142 & $21.1 \%$ & $44.7 \%$ & $87.3 \%$ & $0 \%$ & - & $80.6 \%$ \\
\hline & & (0.044) & & $(0.062)$ & & & & & & \\
\hline \multirow[t]{2}{*}{ NR2 } & 25 & 0.201 & 10 & 0.123 & $0 \%$ & - & $28.6 \%$ & $2.9 \%$ & $100 \%$ & $29.4 \%$ \\
\hline & & $(0.025)$ & & $(0.082)$ & & & & & & \\
\hline \multirow[t]{2}{*}{ NR1 } & 33 & 0.207 & 11 & 0.165 & $0 \%$ & - & $25 \%$ & $2.3 \%$ & $100 \%$ & $25.6 \%$ \\
\hline & & (0.017) & & $(0.060)$ & & & & & & \\
\hline \multirow[t]{2}{*}{ NR0 } & 36 & 0.214 & 8 & 0.198 & $75 \%$ & $84.8 \%$ & $27.3 \%$ & $13.6 \%$ & $100 \%$ & $21.1 \%$ \\
\hline & & (0.029) & & $(0.022)$ & & & & & & \\
\hline
\end{tabular}


Goswami

Table 11: Logistic Regression Results

This table presents logistic regression results on landowners' acceptance decision. The dependent variable equals one when the landowner accepts the offer. Panel A is for initial offers, and Panel B is for offers in the sequential continuation phase. We report the corresponding $z$-statistics in parenthesis. ${ }^{* * *},{ }^{* *}$, and ${ }^{*}$ denote statistical significance at the 1, 5 and 10 percent level for a two-tailed test.

\begin{tabular}{|c|c|c|c|c|c|c|}
\hline \multicolumn{7}{|c|}{ Dependent variable: landowner's acceptance decision } \\
\hline \multicolumn{7}{|c|}{ Panel A. Initial Tender Offers } \\
\hline & \multicolumn{2}{|c|}{ Symmetric Offers } & \multicolumn{2}{|c|}{ Non-symmetric Offers } & \multicolumn{2}{|c|}{ All Offers } \\
\hline \multirow[t]{2}{*}{ OFFER } & 0.152 & 0.044 & 0.179 & 0.123 & 0.082 & \\
\hline & $(2.50) * *$ & $(0.69)$ & $(1.65)^{*}$ & $(1.19)$ & $(1.50)$ & \\
\hline \multirow[t]{2}{*}{ RATIONAL } & & 2.087 & & & 1.110 & \\
\hline & & $(2.75)^{* * *}$ & & & $(2.03)^{* *}$ & \\
\hline \multirow[t]{2}{*}{ MAX } & & & & 0.999 & 0.400 & \\
\hline & & & & $(1.69)^{*}$ & $(0.77)$ & \\
\hline \multirow[t]{2}{*}{ MEANOFFER } & & & & & & 0.142 \\
\hline & & & & & & $(2.78) * * *$ \\
\hline \multirow[t]{2}{*}{ DIFMEAN } & & & & & & 0.334 \\
\hline & & & & & & $(1.34)$ \\
\hline \multirow[t]{2}{*}{ CONST } & -3.766 & -2.739 & -4.545 & -3.981 & -3.366 & -3.753 \\
\hline & $(-3.64)^{* * *}$ & $(-3.09) * * *$ & $(-2.25)^{* *}$ & $(-2.12)^{* *}$ & $(-3.32) * * *$ & $(-4.13) * * *$ \\
\hline $\mathrm{N}$ & 99 & 99 & 81 & 81 & 180 & 180 \\
\hline \multirow[t]{3}{*}{ Pseudo $\mathrm{R}^{2}$} & 0.097 & 0.186 & 0.044 & 0.079 & 0.112 & 0.073 \\
\hline & Panel B. O & fers in the & Sequential & Continuation & n Phase & \\
\hline & NR2 & NR1 & & R0 & All C & Offers \\
\hline \multirow[t]{2}{*}{ OFFER } & 0.911 & 0.587 & 0.213 & 0.207 & 0.311 & 0.302 \\
\hline & $(1.99)^{* *}$ & $(1.90)^{*}$ & $(1.20)$ & (1.09) & $(2.93) * * *$ & $(3.12) * * *$ \\
\hline \multirow[t]{2}{*}{ MAX } & -9.330 & 0.888 & -0.194 & & -0.130 & -0.138 \\
\hline & $(-1.55)$ & $(0.76)$ & $(-0.15)$ & & $(-0.16)$ & $(-0.17)$ \\
\hline \multirow[t]{2}{*}{ RATIONAL } & & & & -0.095 & -0.266 & \\
\hline & & & & $(-0.08)$ & $(-0.43)$ & \\
\hline \multirow[t]{2}{*}{ RESIDUAL } & & & & & & -0.004 \\
\hline & & & & & & $(-0.51)$ \\
\hline \multirow[t]{2}{*}{ CONST } & -7.238 & -11.174 & -2.741 & -2.699 & -4.647 & -4.332 \\
\hline & $(-1.85)^{*}$ & $(-1.86)^{*}$ & $(-0.89)$ & $(-0.80)$ & $(-2.62) * * *$ & $(-2.64) * * *$ \\
\hline $\mathrm{N}$ & 35 & 44 & 44 & 44 & 123 & 123 \\
\hline Pseudo $\mathrm{R}^{2}$ & 0.398 & 0.255 & 0.052 & 0.051 & 0.191 & 0.192 \\
\hline
\end{tabular}

